NASA Technical Memorandum 4800

\title{
Supersonic Flying Qualities Experience Using the SR-71
}

Timothy H. Cox

Dryden Flight Research Center

Edwards, California

Dante Jackson

Analytical Services and Material, Inc.

Edwards, California

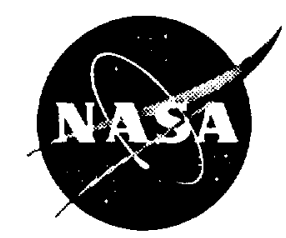

National Aeronautics and Space Administration

Office of Management

Scientific and Technical Information Program 



\title{
SUPERSONIC FLYING QUALITIES EXPERIENCE USING THE SR-71
}

\author{
Timothy H. Cox \\ NASA Dryden Flight Research Center \\ Edwards, California \\ Dante Jackson \\ AS\&M \\ Edwards, California
}

\begin{abstract}
$\underline{\text { Abstract }}$
Approximately 25 years ago NASA Dryden Flight Research Center, Edwards, California, initiated the evaluation of supersonic handling qualities issues using the XB-70 and the YF-12. Comparison of pilot comments and ratings with some of the classical handling qualities criteria for transport aircraft provided information on the usefulness of these criteria and insight into supersonic flying qualities issues. A second research study has recently been completed which again addressed supersonic flying qualities issues through evaluations of the SR-71 in flight at Mach 3. Additional insight into supersonic flying qualities issues was obtained through pilot ratings and comments. These ratings were compared with existing military specifications and proposed criteria for the High Speed Civil Transport. This paper investigates the disparity between pilot comments and the Neal/Smith criteria through a modification of the technique using vertical speed at the pilot station. The paper specifically addresses the pilot ability to control flightpath and pitch attitude in supersonic flight and pilot displays typical of supersonic maneuvering.
\end{abstract}

\section{Nomenclature}

ADI attitude director indicator

bw bandwidth

CAP control anticipation parameter

c.g. center of gravity

*Aerospace Engineer

Aerospace Engineer

Copyright (c) 1997 by the American Institute of Aeronautics and Astronautics, Inc. No copyright is asserted in the United States under Title 17, U.S. Code. The U.S. Government has a royalty-free license to exercise all rights under the copyright claimed herein for Governmental purposes. All other rights are reserved by the copyright owner

\begin{tabular}{|c|c|}
\hline $\mathrm{CH}$ & Cooper-Harper rating \\
\hline 8 & acceleration due to gravity \\
\hline IVSI & instantaneous vertical speed indicator \\
\hline KEAS & knots equivalent airspeed \\
\hline$L_{\alpha}$ & lift curve slope of the aircraft, lbf \\
\hline NASA & $\begin{array}{l}\text { National Aeronautics and Space } \\
\text { Administration }\end{array}$ \\
\hline $\mathbf{s}$ & LaPlace operator \\
\hline SAS & stability augmentation system \\
\hline $1 / T_{\theta_{2}}$ & high-frequency pitch attitude zero, $\mathrm{rad} / \mathrm{sec}$ \\
\hline$\Delta$ & the change in a parameter \\
\hline$\theta$ & pitch attitude, deg \\
\hline$\theta_{c}$ & pitch attitude command, deg \\
\hline$\tau_{p}$ & bandwidth time delay parameter, sec \\
\hline$\phi$ & phase angle, deg \\
\hline$\phi_{2 \omega_{180^{\circ}}}$ & $\begin{array}{l}\text { phase angle at twice the phase crossover } \\
\text { frequency, rad/sec }\end{array}$ \\
\hline$\omega_{b w_{\text {gain }}}$ & $\begin{array}{l}\text { gain-limited pitch attitude bandwidth } \\
\text { parameter, rad/sec }\end{array}$ \\
\hline$\omega_{b w_{\text {phase }}}$ & $\begin{array}{l}\text { phase-limited pitch attitude bandwidth } \\
\text { parameter, } \mathrm{rad} / \mathrm{sec}\end{array}$ \\
\hline$\omega_{b w_{\gamma}}$ & flightpath bandwidth parameter, $\mathrm{rad} / \mathrm{sec}$ \\
\hline$\omega_{b w_{\theta}}$ & pitch attitude bandwidth parameter, $\mathrm{rad} / \mathrm{sec}$ \\
\hline$\omega_{s p}$ & short period frequency, $\mathrm{rad} / \mathrm{sec}$ \\
\hline$\omega_{180^{\circ}}$ & phase crossover frequency, $\mathrm{rad} / \mathrm{sec}$ \\
\hline
\end{tabular}

Introduction

Good handling qualities are essential for aircraft performance and can be predicted during the design process by analytic means. Handling qualities criteria used to evaluate aircraft designs are defined by empirical 
data obtained from previous aircraft. A problem exists, however, when an aircraft flies in a new flight regime. Airplanes cruising at speeds greater than Mach 2 or beyond are examples of this problem.

Flying qualities criteria do not address some of the unique characteristics of high-speed flight because they are based primarily on subsonic data. For example, many of the current criteria assume that good flightpath response follows from good pitch attitude response; however for the high-speed case, this assumption may not be valid. As Mach number increases, the lift curve slope of an aircraft $\left(L_{\alpha}\right)$ decreases proportionally, thereby increasing the lag between flightpath and pitch attitude response. If this lag characteristic is too large, the pilot's ability to control flightpath will be impaired.

Another unique characteristic of high-speed flight is the decrease in pitch attitude change to achieve a rate of climb. This characteristic, due primarily to the increased velocity, implies that as the speed increases the pilot must maintain precise control of pitch attitude to establish the desired altitude response. Unless accurate pitch attitude or rate-of-climb information is fed back to the pilot, this characteristic could potentially cause the pilot to overcontrol the aircraft. This increased sensitivity to pitch attitude control in high-speed flight is not as prevalent in subsonic flight. Nevertheless, flying qualities criteria of pitch attitude are based on subsonic data.

Approximately 25 years ago NASA Dryden Flight Research Center researchers gained insight into these issues by applying MIL-STD-8785B criteria ${ }^{1}$ to YF-12 and XB-70 data. The longitudinal tasks for the YF-12 and XB-70 transport class aircraft, in up and away flight, included precise flightpath tracking without gross maneuvering, which was considered category $\mathrm{C}$ flight. The researchers showed for both the YF-12,3,4 and the $\mathrm{XB}-70^{2,5}$ positive correlation between category $\mathrm{C}$ criterion on the control anticipation parameter (CAP) and pilot comments and ratings. The researchers also indicated the requirements for short period damping may be relaxed although these results were not considered conclusive. ${ }^{4.5}$ Researchers also gained insight into unique issues of supersonic cruise flight, such as the usefulness of an inertial vertical speed display ${ }^{2,3}$ and the problems associated with unstable long period dynamics. 2,6

Recently a second study was completed which extends the research of supersonic flying qualities issues conducted by the XB-70 and YF-12 programs through evaluations of the SR-71 aircraft in flight at Mach 3. Data includes pilot comments and ratings of the SR-71 flown with a well-defined vertical altitude plane change maneuver. Data from this study were used to assess the applicability of handling qualities criteria, especially those used in the design of the High Speed Civil Transport program. ${ }^{7}$

A comparison of the pilot's ability to directly control flightpath and pitch attitude in supersonic flight and an evaluation of the vertical speed display are specifically addressed in this report. The Neal/Smith criteria, ${ }^{8}$ bandwidth criteria on pitch attitude, ${ }^{8}$ and bandwidth criteria on flightpath ${ }^{9}$ are used to evaluate pilot control of fightpath and pitch attitude. Throughout the analysis, results of these criteria are compared with the piloted evaluations. In all cases, criteria for category $C$ flight were assumed to be applicable to the high-speed tasks.

\section{Aircraft Description}

The SR-71 aircraft (fig. 1) is a twin engine, delta-wing airplane designed to cruise at a speed of Mach 3.2 and to altitudes above $80,000 \mathrm{ft}$. The SR-71 aircraft is powered by two Pratt \& Whitney (West Palm Beach, Florida) J-58 afterburner engines with axisymmetric, variablegeometry, mixed compression inlets. Centerbody spikes and bypass doors located on the forward part of the nacelle are automatically modulated to control the oblique and normal shock positioning that is associated with flying at high supersonic speeds. Data gathered in this report occurred with doors and inlets in this automatic configuration.

The majority of the cockpit contains conventional instrumentation. Some of the main cockpit instruments used during this evaluation include a pressure-driven instantaneous vertical speed indicator (IVSI) and a triple display indicator that shows altitude, equivalent airspeed, and Mach number in a digital format. The IVSI is a circular gauge with a needle indicating vertical speed to a resolution of $100 \mathrm{ft} / \mathrm{min}$. The resolutions of the triple display indicator parameters are $50 \mathrm{ft}, 1 \mathrm{kn}$, and Mach 0.01 , respectively. Because a lag in the response of the IVSI exists at high altitude, a horizontal needle displaying inertial vertical speed located on the attitude director indicator (ADI) provides a reference for climb and descent rates. This gives SR-71 pilots a more precise and reliable vertical speed indicator than the IVSI.

Wing trailing-edge elevons are used symmetrically as elevators and differentially as ailerons to provide longitudinal and lateral control, while twin all-movable vertical tails supply directional control. The pilot 


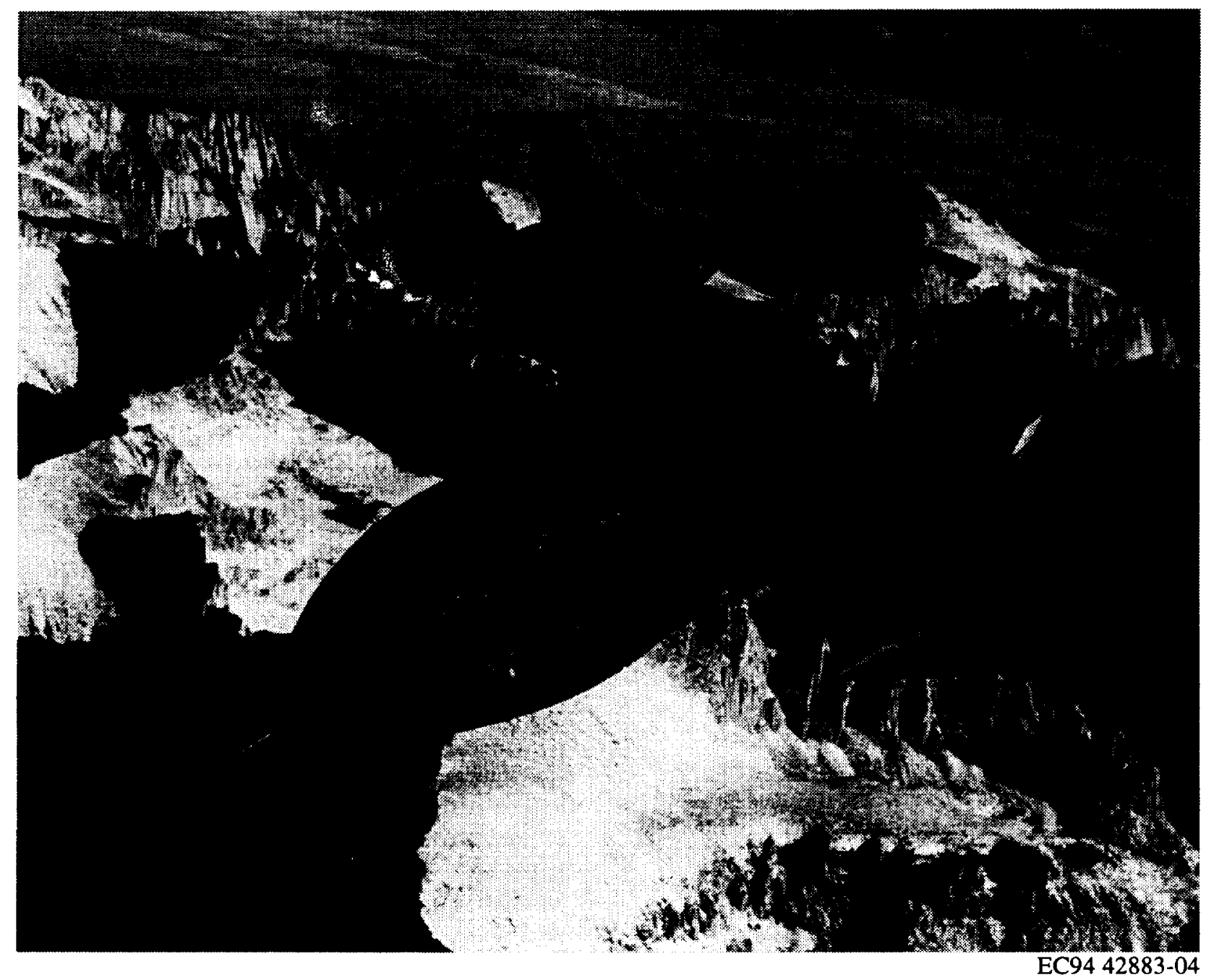

Figure 1. SR-71 aircraft.

controls consist of a conventional stick for pitch and roll inputs and rudder pedals for yaw inputs. The SR-71 aircraft has a conventional response with angle-of-attack and normal acceleration changes commanded by the pitch stick. The controls are irreversible and fully powered by two independent $3000 \mathrm{lb} / \mathrm{in}^{2}$ hydraulic systems that operate actuating cylinders at each control surface.

The SR-71 flight control system provides a stability augmentation system (SAS) to increase damping about all three axes. This is accomplished with conventional feedback of roll rate, pitch rate, and yaw rate. In addition, lateral acceleration is used in the yaw axis to reduce the severity of engine unstarts.

An autopilot is available to reduce the workload involved in flying the SR-71 aircraft. The autopilot includes attitude hold (in pitch, roll, or both), Mach number hold, and knots equivalent airspeed (KEAS) hold. Normal aircraft maneuvering is executed by pitch and roll attitude inputs through thumbwheels, while acceleration and deceleration to and from Mach 3 are performed with KEAS hold engaged on the autopilot. The autopilot mode is used routinely in the climb, cruise, and descent portions of the flights. However for the handling qualities evaluations, all autopilot modes were disengaged, and maneuvers were performed manually with the stick.

\section{Maneuver Description and Pilot Evaluations}

Three maneuvers were flown at Mach 3 to evaluate the handling qualities characteristics of the SR-71 aircraft: a steady level turn, an ascending turn, and a vertical plane altitude change. These maneuvers were considered to be 
typical of maneuvers to be flown by a large supersonic transport aircraft. Reference 7 describes each maneuver and documents pilot comments and ratings. For the purpose of this paper, only the description and evaluation of the vertical plane altitude change is considered.

Two pilots flew the maneuver a total of five times. Pilot ratings and comments evaluating each maneuver using predefined adequate and desired performance margins were collected immediately after performing each task and during postflight briefings.

\section{Maneuver Description}

The vertical plane altitude change at constant KEAS entailed a wing level pullup to capture a $2000-\mathrm{ft}$ altitude increment at a climb rate of $1000 \mathrm{ft} / \mathrm{min}$. Once the target altitude was established, it was to be held for an additional $10 \mathrm{sec}$. Constant airspeed was to be maintained throughout the maneuver. The pilots evaluated this maneuver with two variations of feedback displays: one using the IVSI and the other using the inertial vertical speed on the ADI.

Adequate margins for the maneuver were $\pm 300 \mathrm{ft}$ deviation from target altitude and \pm 10 KEAS deviation from target airspeed. Desired margins for this maneuver were $\pm 100 \mathrm{ft}$ deviation from target altitude and \pm 5 KEAS deviation from target airspeed.

\section{Summary of Pilot Evaluations}

Pilots' comments using the IVSI and the inertially derived vertical speed are summarized below for the vertical plane altitude change. Figure 2 presents the Cooper-Harper $(\mathrm{CH})$ ratings for pilots $\mathrm{A}$ and $\mathrm{B}$.

\section{IVSI}

Flying the maneuver with the IVSI as a vertical speed indicator made establishing and maintaining the desired rate of climb very difficult. This is caused by sluggish initial response and an excessive delay between the stick input and a reaction in the IVSI gauge. The altitude change was able to be performed but not without high concentration and some loss of performance. The ability of the pilot to hold airspeed was decreased because of the excursions in rates of climb. These problems warranted ratings of $\mathrm{CH}=5-7$ (levels 2-3).

\section{Inertially Derived Vertical Speed}

Flying the maneuver using the inertial derived vertical speed for feedback made achieving desired performance relatively easy. The desired rate of climb was easy to

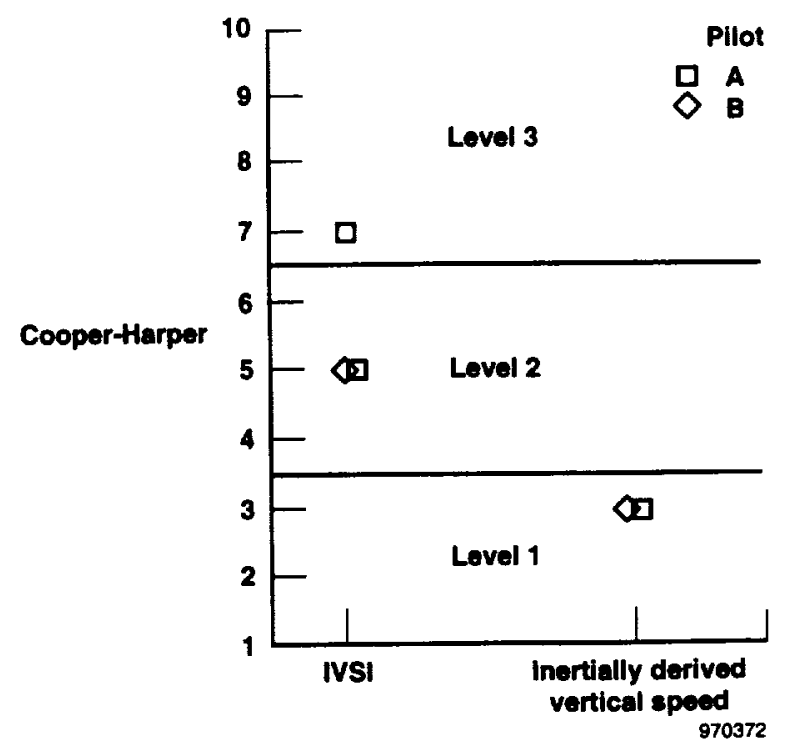

Figure 2. Pilot ratings for the vertical plane altitude change maneuver.

establish. As long as enough range of throttle motion in afterburner was available, the airspeed was easily maintained as well. The only difficulty arose when searching to establish rate of climb and when leading the aircraft as it approached the target altitude. This minor compensation required in establishing flightpath added to the basic concentration necessary to fly this airplane and warranted $\mathrm{CH}=3$ (level 1 ).

\section{Pilot Display of Vertical Speed}

This section presents insight on the pilot display of vertical speed necessary for typical maneuvering in highspeed flight. As was mentioned earlier, the vertical plane altitude change maneuver was flown using two types of vertical speed indicators as feedback to the pilot: a pressure-driven one (IVSI) and an inertially derived one. Figure 3 compares the altitude time histories of two

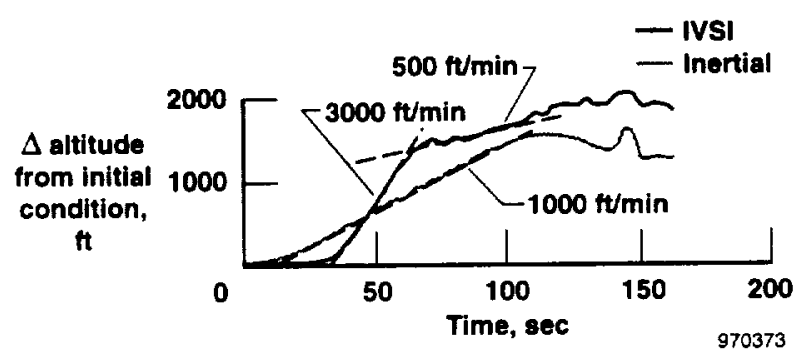

Figure 3. Comparison of the vertical plane altitude change maneuver using the IVSI and an inertially derived vertical speed indicator. 
vertical plane altitude change maneuvers. One maneuver was flown using the IVSI and the other was flown with the inertially derived vertical speed. This figure plots the increment in altitude from the initial altitude for each of the maneuvers to provide a common reference point for comparison.

It is clear from observing the maneuver flown with the IVSI that the pilot was unable to establish the correct rate of climb ( $1000 \mathrm{ft} / \mathrm{min})$. Instead, the pilot overshot rate of climb by $a$ factor of 3 and then overcompensated to $500 \mathrm{ft} / \mathrm{min}$. By reducing the rate of climb to $500 \mathrm{ft} / \mathrm{min}$, the pilot was able to hit the target altitude within the desired performance of $100 \mathrm{ft}$. The pilot comment on this maneuver was "rate of climb [is] all over the place. Could not keep rate of climb anywhere near where I wanted it." The corresponding pilot rating was $\mathrm{CH}=5$. The difficulty in performing the maneuver derived from the lags in the pressure-driven IVSI. The static pressure decreases which are associated with high altitude make changes in altitude difficult to measure. Thus, the pilot tends to overdrive rate of climb. Figure 4 shows the relative amounts of lag contributed by the IVSI and the flightpath response lag, $1 / T_{\theta_{2}}$, as a function of altitude. ${ }^{2}$ At an altitude of $70,000 \mathrm{ft}$, nearly $12 \mathrm{sec}$ of lag is present, one-half of which is caused by the IVSI. One pilot concluded that the "vertical velocity indication has a very long lag, and the pilot cannot use it as a feedback variable."

In contrast, the ability of the pilot to establish the $1000 \mathrm{ft} / \mathrm{min}$ rate of climb was greatly improved when the maneuver was flown with the inertially derived vertical speed (fig. 3). Although the pilot misjudged the target altitude by $500 \mathrm{ft}$, he was able to establish the desired altitude precisely. Pilot comments indicated that this maneuver was "to some extent a nonevent. You establish the $1000 \mathrm{ft} / \mathrm{min}$ and then sort of nod off. You establish a new trim and then be alert enough to see when you want to start to level off. I held 75,500 right on at the level off. This is easy to do." The pilot rating for this maneuver was much improved also, $\mathrm{CH}=3$ (level 1). The conclusion is that to accurately control flightpath the pilot must have an inertially derived vertical speed indication.

\section{Pilot Control of Pitch Attitude and Flightpath}

This section presents insight into whether it is more appropriate for the pilot to control pitch attitude or flightpath for maneuvering typical of high-speed flight. Pilots typically control flightpath by commanding a pitch attitude change and then waiting for the desired flightpath to develop. This technique applies to normal,

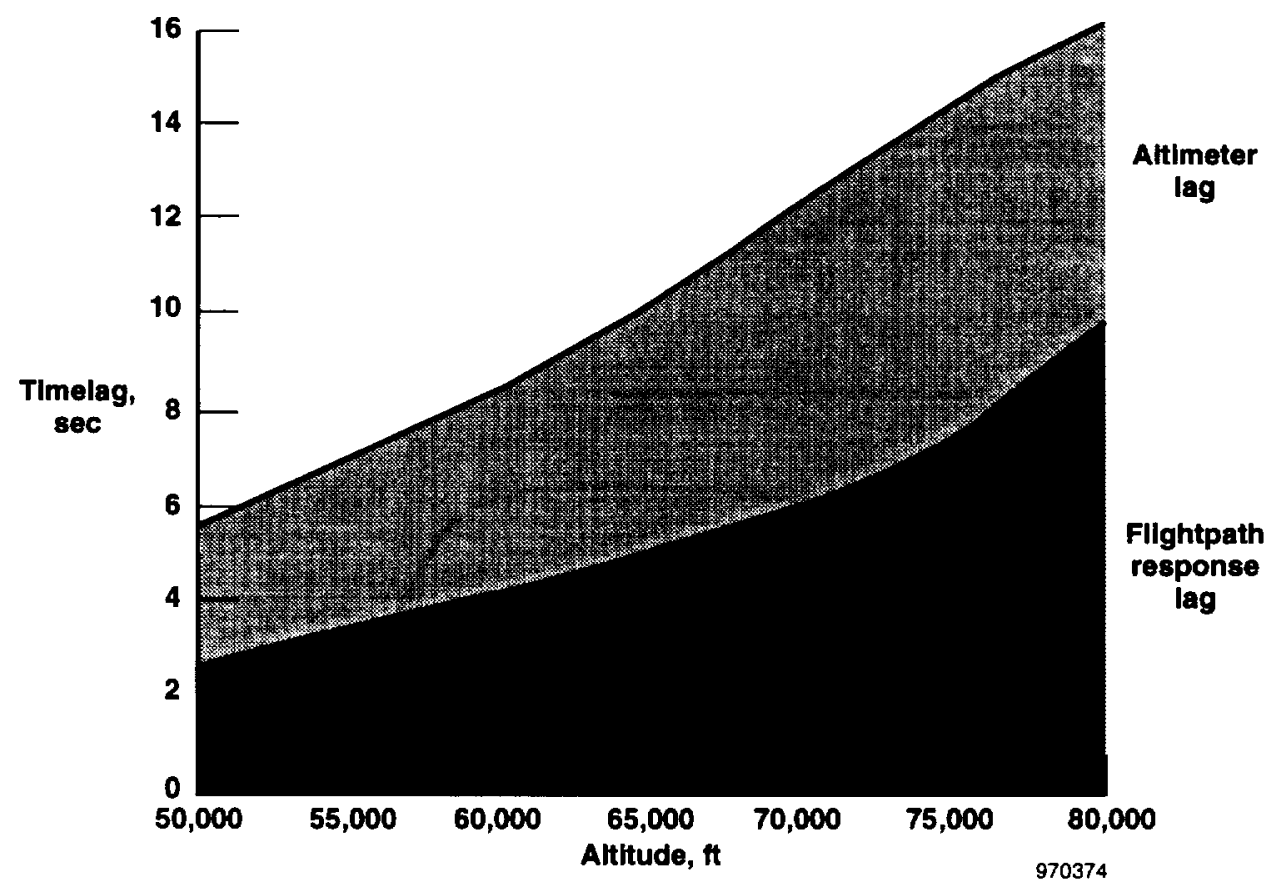

Figure 4. Relative time lag comparison of flightpath response and altimeter. ${ }^{2}$ 
subsonic flight when the pilot uses pitch attitude as the feedback parameter either through visual cues obtained by looking out the canopy window or through the ADI. For conventional aircraft in subsonic flight, this technique is generally successful. On the other hand, how does this apply to high-speed flight, where the increase in lag of the flightpath response may make this technique unusable? In such a case, direct pilot control of flightpath may be more appropriate. To directly control flightpath, the pilot must use either flightpath or vertical speed as the feedback parameter.

Several analysis techniques are used to evaluate the pilots' ability to control pitch attitude and flightpath: pitch bandwidth analysis, pitch bandwidth as a function of flightpath bandwidth analysis, frequency response analysis, and Neal/Smith analysis. To evaluate the analysis techniques, the results from criteria are compared with the ratings and comments from the maneuvers using the inertially derived vertical speed indication.

Reproduced YF-12 data were used to supplement the SR-71 handling qualities data for some of the analysis. Enough information existed in the reference 3 report to extract the test conditions of the YF-12 data. Because of the similarity of the YF-12 and SR-71 aircraft in the longitudinal axis, a flight-validated SR-71 linear simulation was used to model the YF-12 data.

\section{Pitch Bandwidth}

To analyze pitch attitude control, the pitch bandwidth criterion as defined in MIL-STD- $1797^{\circ}$ was evaluated with SR-71 and reproduced YF-12 data. The gain-limited bandwidth, defined as the frequency at the magnitude which is $6 \mathrm{~dB}$ above the magnitude at the phase crossover frequency, and phase limited bandwidth, defined as the frequency where a $45^{\circ}$ phase margin exists, were calculated from a pitch attitude from stick deflection frequency response. The lesser of the two frequencies was considered the bandwidth frequency. This criterion places limits on the bandwidth frequency as a function of the time delay, which is estimated from the phase at twice the phase crossover frequency:

$$
\tau_{p}=\frac{\phi_{2 \omega_{180^{\circ}}}+180^{\circ}}{57.3\left(2 \omega_{180^{\circ}}\right)}
$$

The calculation of the bandwidth frequency for SR-71 and YF-12 data with the SAS turned on proved straightforward. However, the YF-12 data included four test points where the SAS was turned off. A typical example of the pitch attitude bandwidth calculation for low damped, SAS turned off, YF-12 data is shown in figure 5. The calculation of the phase bandwidth value, the frequency where the phase is $-135^{\circ}$, is straightforward. However, the calculation of the gain

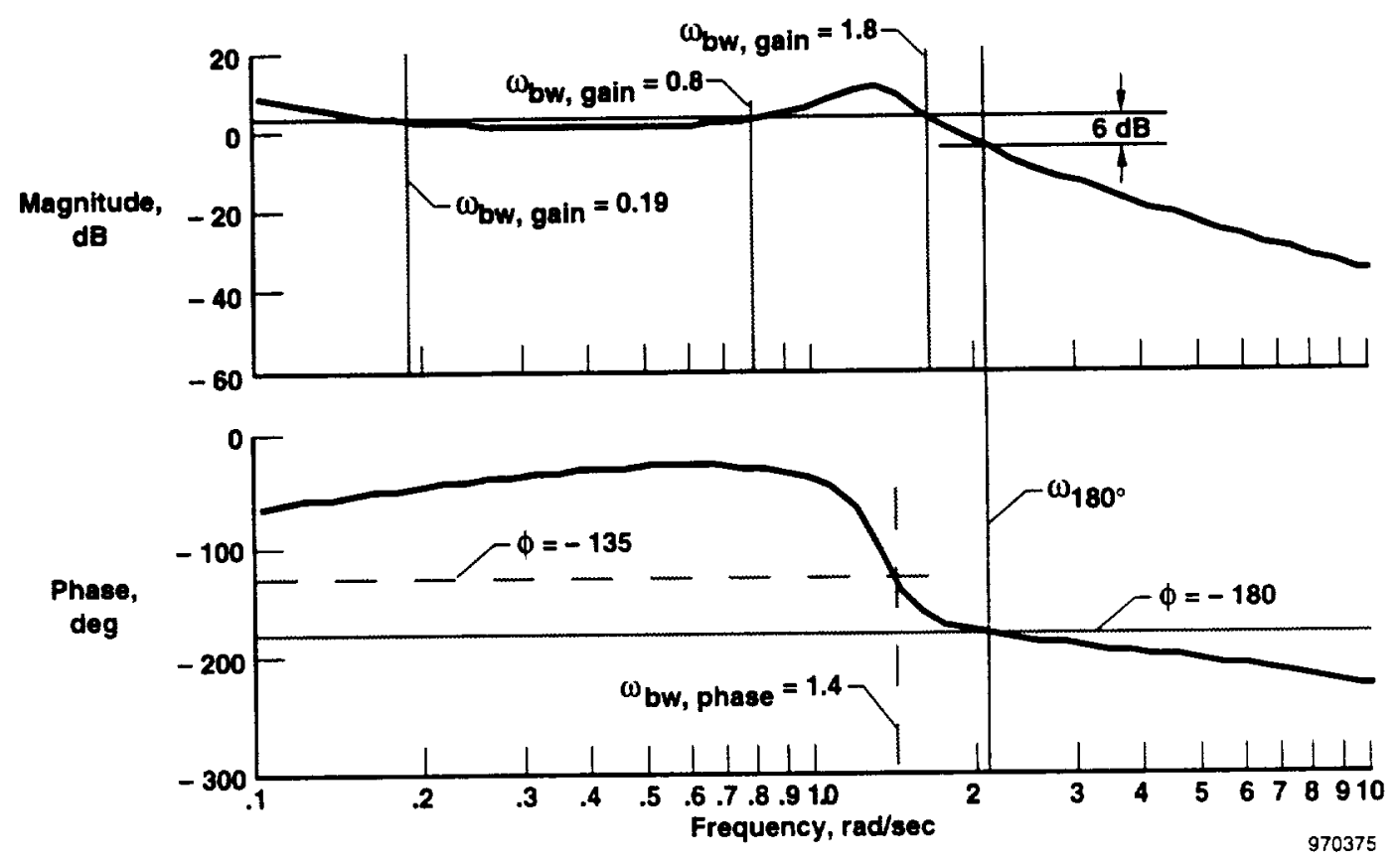

Figure 5. Example pitch attitude bandwidth calculation typical of a low damped YF-12 test point. 
bandwidth value is less obvious. Applying the definition of the gain-limited bandwidth to the data in figure 5 results in three possible gain bandwidth values: $1.8,0.8$, and $0.19 \mathrm{rad} / \mathrm{sec}$. Note that a slightly increased phase crossover frequency, $\omega_{180^{\circ}}$, would prevent this phenomenon from occurring. If the value of $1.8 \mathrm{rad} / \mathrm{sec}$ were considered the gain bandwidth value, then the phase bandwidth value would be compared to the criterion since it is less than $1.8 \mathrm{rad} / \mathrm{sec}$. However, if either the 0.8 or $0.19 \mathrm{rad} / \mathrm{sec}$ values are the appropriate gain bandwidth value, then these values would be compared to the criterion because they are less than the phase bandwidth value.

This phenomenon results because of the large, shelflike characteristic created by the significant difference between $1 / T_{\theta_{2}}$ and the short period frequency as well as the low short period damping. The low short period damping characteristic produces the three possible gain bandwidth values. Standard procedure for the application of this criterion would be to choose the lesser value, $0.19 \mathrm{rad} / \mathrm{sec}$, as the gain bandwidth. The rationale is that if the pilot tries to close the loop at the higher gain bandwidth values a tendency to oscillate will occur because of the lightly damped peak. The large, shelf-like characteristic produces a wide separation between the three gain bandwidth values. The existence of a large shelf is generally an indication of poor handling qualities, because the gain margin is very sensitive to slight changes in phase. ${ }^{8}$ The results of the analysis using the lowest gain bandwidth (represented by $0.19 \mathrm{rad} / \mathrm{sec}$, fig. 5) and the phase bandwidth are compared in the following discussion.

Figure 6 shows the pitch bandwidth results. The pilot ratings for each point are plotted next to the point. The analysis indicates that good pilot control of pitch attitude is possible with the SAS turned on. The level 1 pilot ratings of these two points correlate with the analysis. When the SAS is turned off and the damping decreases, pitch bandwidth decreases. In addition, pilot control of pitch attitude deteriorates. The amount of deterioration in the predicted pilot control of pitch attitude depends on whether the gain or phase-limited bandwidths are used in the analysis. Use of the gain-limited bandwidths drastically reduces the pitch bandwidth to around 0.25 , near the level 3 border. The pilot ratings, which are mainly level 2, appear to correlate better with the phaselimited bandwidth values. Although the reason behind this phenomenon is unknown, it may be that ignoring the two lower frequency gain-limited bandwidths is appropriate for this type of transfer function.

Although the pitch bandwidth analysis is supported with pilot evaluations and indicates that good pitch attitude control is possible, it may be a misleading result.

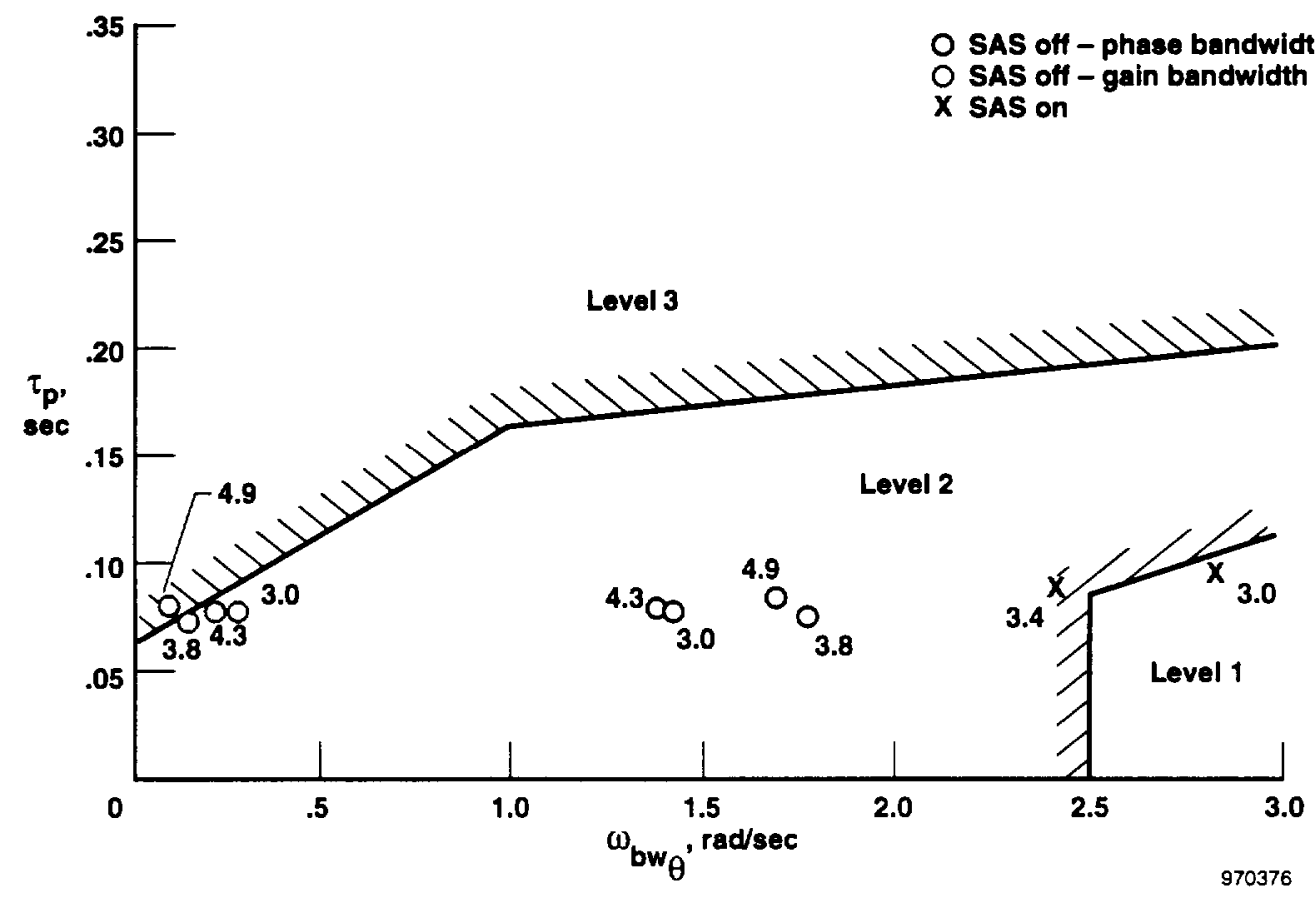

Figure 6. MIL-STD-1797 pitch bandwidth criteria for category C flight. 
Because the vertical speed indicator is the primary feedback display, the pilot ratings and comments appear driven more by the flightpath response than the pitch attitude response. Thus, it is uncertain whether the bandwidth analysis, which assumes pilot feedback of pitch attitude, accurately reflects the pilot evaluations. The level 2 pilot evaluations of the SAS turned off data could reflect degraded flightpath response and not degraded pitch attitude response. In this case, the pilot may not even care about pitch attitude response, and the correlation of the pilot ratings with the phase-limited pitch attitude bandwidth may be coincidental.

The pitch attitude bandwidth analysis for the SAS turned on data in figure 6 may also be misleading because of the existence of the large shelf in the pitch attitude frequency response. Reference 8 documents the potential of a frequency response which has a large shelf and a gain-margin-limited bandwidth frequency to provide bandwidth frequency estimates that give optimistic predictions of handling qualities. Although the SAS turned on bandwidth frequency estimates are phase margin limited, the gain-margin-limited frequencies are very close to the phase-margin-limited frequency, and both fall right on the edge of the shelf. Small changes in gain could provide for large reductions in phase margin, providing misleading predictions of pitch attitude control. Thus, although good pitch attitude bandwidth exists, it may not necessarily relate to good flying qualities if the pilot were to control pitch attitude.

Pitch Bandwidth as a Function of Flightpath Bandwidth Analysis

Because pilot comments and ratings appear linked to flightpath response, applying an additional criterion on flightpath bandwidth may be insightful. A criterion on flightpath bandwidth as a function of pitch attitude bandwidth was evaluated against SR-71 and reproduced YF-12 data (fig. 7). Phase bandwidth values of pitch bandwidth are used for the SAS turned off YF-12 data.

The SAS turned on data falls well within the level 1 region for both flightpath and pitch attitude bandwidth. This analysis indicates that good pilot control of pitch attitude and flightpath control is possible. However, the addition of the SAS turned off YF-12 data reduces the pitch attitude bandwidth and increases the flightpath bandwidth enough to be near the border between levels 2 and 3. Because pilot ratings appear more dependent on flightpath than on pitch attitude, the increase in flightpath bandwidth could be a factor which degrades the SAS turned off evaluations although the pilot ratings are better than what would be predicted by this criterion. Still, it is unclear whether the degradation results from the increase in flightpath bandwidth or the decrease in pitch attitude bandwidth.

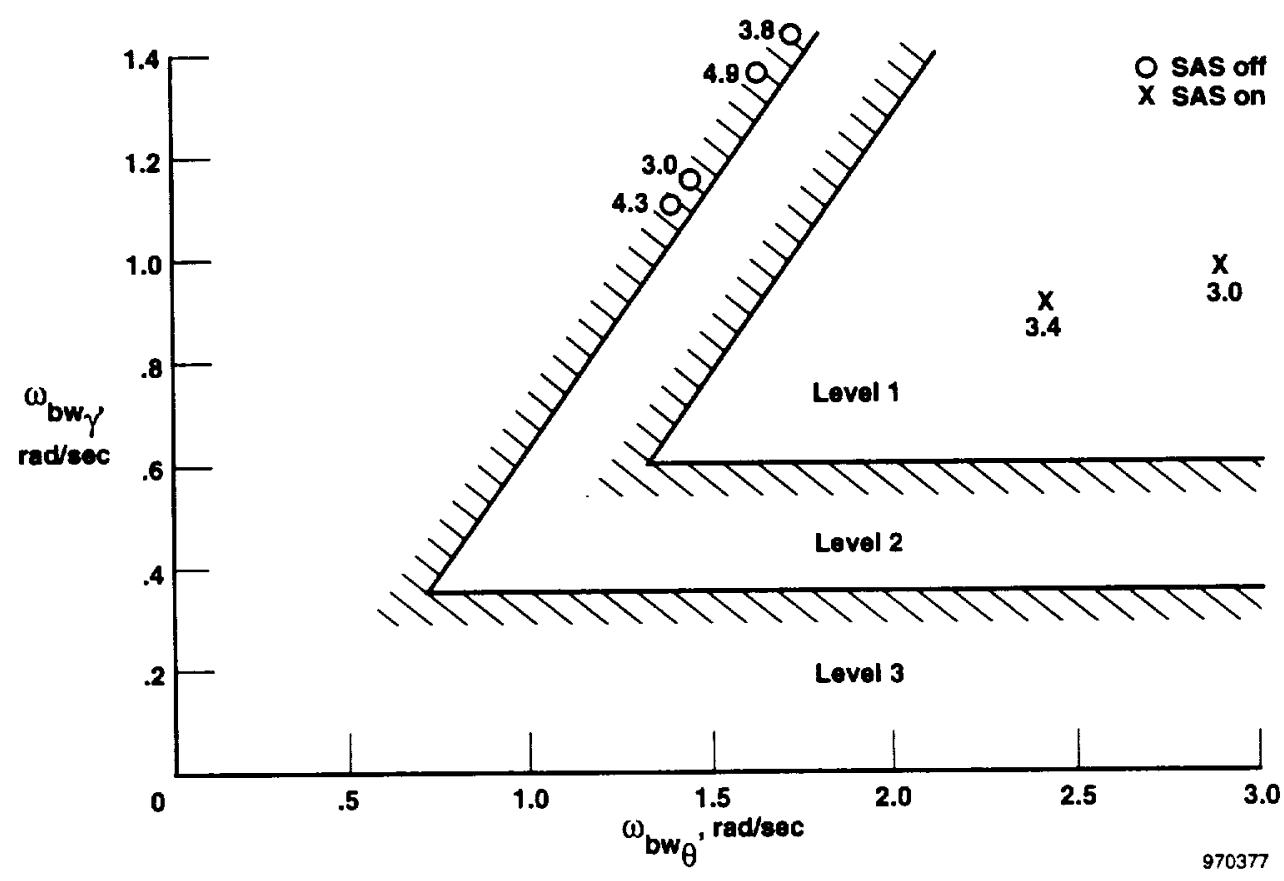

Figure 7. Criteria on pitch bandwidth vs. flightpath bandwidth. 
Closer scrutiny of the flightpath bandwidth data shows some problems, however. This criterion sets requirements on the amount of lag between pitch attitude and flightpath response. The flightpath bandwidth values for the SAS turned off data in figure 7 are above the level 1 region. This implies that the flightpath response lags the pitch attitude, not by too much as is expected, but by too little. This result is counter intuitive because physically the lag between pitch attitude and flightpath increases with Mach number. If flightpath bandwidth were the cause of the degradation in pilot ratings between the SAS turned on and turned off data, the SAS turned off data would be expected to be below the level 1 flightpath bandwidth limit (at 0.6), not above. Thus, pilot evaluations are inconclusive in supporting these criteria.

One possible explanation for this data is that the upper limit on flightpath bandwidth was set based on the need to separate the pitch attitude and flightpath responses for precision approach and landing. In this flight phase, both pitch attitude and flightpath response need to be controlled by the pilot. For the data in figure 7 , the pilot ratings appear to be based only on flightpath control. The separation requirement between flightpath and pitch attitude response may not be as important for these conditions. The pilot simply may not care as much about the smaller pitch attitude response in cruise flight as compared to landing.

\section{Frequency Response Analysis}

Additional insight on the issue of whether it is more appropriate to control flightpath or pitch attitude is provided through figure 8 . This figure presents a comparison of the magnitude of the pitch attitude and flightpath from stick deflection frequency responses with the SAS turned on. These frequency responses were generated with an SR-71 linear model that was validated with flight data. A large shelf exists in the pitch attitude frequency response which is normally associated with bad pitch attitude control. The large shelf exists because of the significant separation in $1 / T_{\theta_{2}}$ (which causes the lag between flightpath and pitch attitude) and short period frequency $\left(\omega_{s p}\right)$. However, the large shelf is actually the cause of good flightpath control. For the frequency range where the large shelf exists, the flightpath frequency response is characteristic of an integrator, or $1 / \mathrm{s}$. The $1 / \mathrm{s}$ characteristic is typical of aircraft with good flying qualities. Thus, pilot control of flightpath should be better than pitch attitude control. Other types of control systems could remove the shelf improving pitch attitude control, such as pitch rate command systems. However, such systems would cause flightpath control to deteriorate.

\section{Neal/Smith Analysis}

The Neal/Smith criterion typically involves closing the loop around a pitch-attitude-to-stick-deflection transfer function and a lead-in-lag compensator. This procedure is modified by the addition of pure time delay, to meet specific closed-loop characteristics. The characteristics of the closed-loop frequency response are defined as $-90^{\circ}$ of phase at the bandwidth frequency and no less than $-3 \mathrm{~dB}$ of droop (fig. 9). The bandwidth frequency represents the piloting task which is being conducted and is generally chosen based on flight phase. Criteria are established based on the lead required of the compensator to meet the characteristics and the maximum amplitude, or resonant peak, of the frequency response of the closed-loop system; for example, the compensator and airplane.

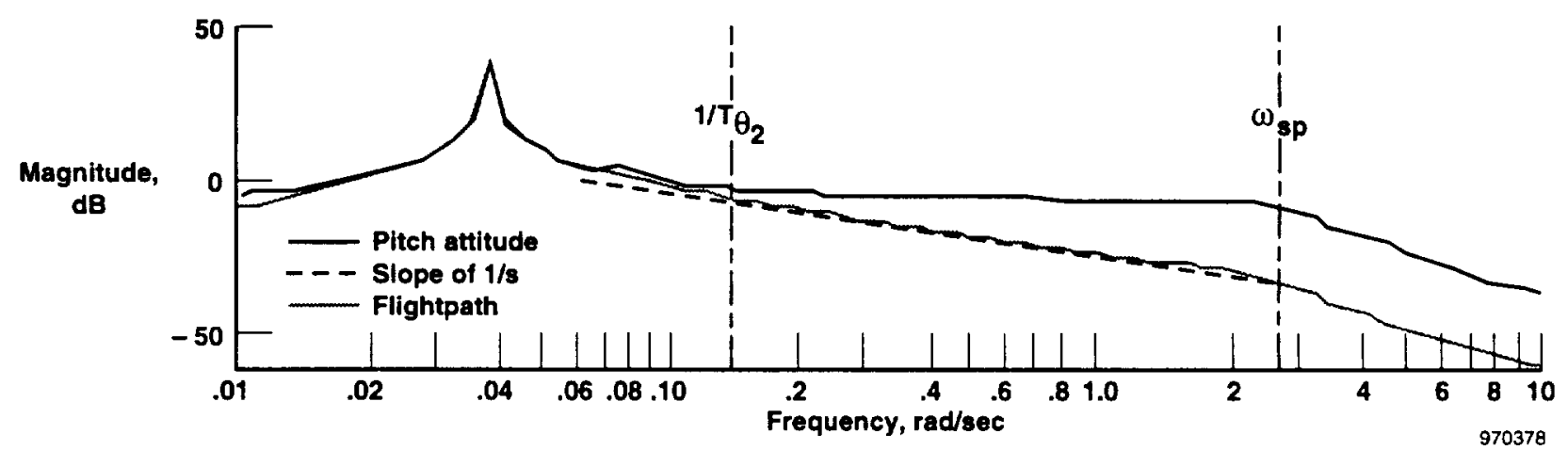

Figure 8. Comparison of pitch attitude and flightpath from stick position frequency response. 


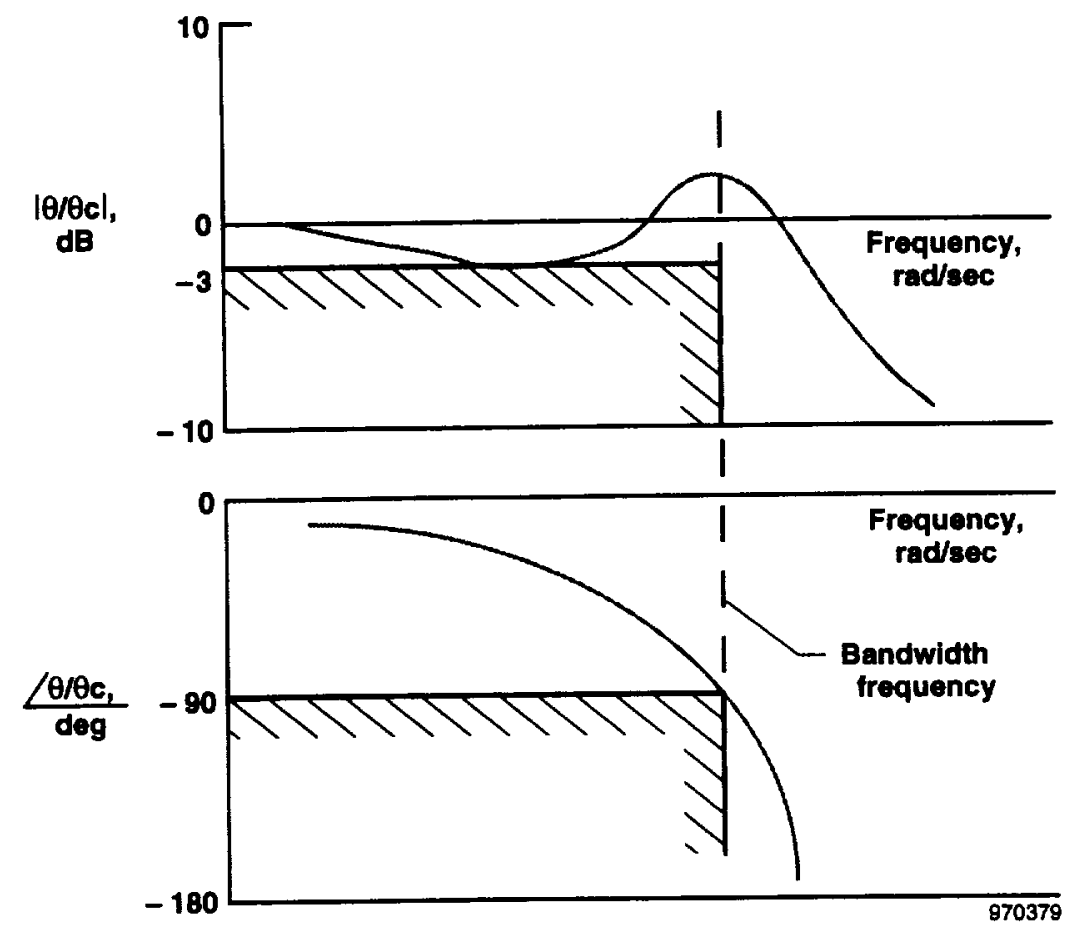

Figure 9. Illustration of application of Neal/Smith criteria.

To examine the issue of whether pilot control of pitch attitude or flightpath is more appropriate, the Neal/Smith criteria were applied to SR-71 flight data at Mach 3.0 using frequency responses of pitch attitude from stick deflection and vertical speed from stick deflection. The vertical speed data were obtained by integrating the normal acceleration at the pilot station. (The inertially derived vertical speed was calculated by the navigation system, which is located just aft of the cockpit.) The data presented here use $0.3 \mathrm{sec}$ as the time delay of the compensator. Three bandwidths ranging from 1.5 to $2.5 \mathrm{rad} / \mathrm{sec}$ were analyzed with the pitch attitude frequency response to evaluate the results for increases in the demands of the task. Bandwidth from 1.0 to 2.0 were analyzed for the vertical speed frequency response.

Figure 10 presents the results comparing the two frequency responses. For the compensator using pitch attitude, significant amounts of pilot lag are required, driving the flying qualities into the level 2 region. Level 1 ratings from bandwidths of 1.0 to 1.5 result with the compensator using vertical speed, which was consistent with pilot comments. In addition, the slope of degradation ( $\Delta$ resonant peak/ $\Delta$ pilot lead) as bandwidth increases using vertical speed is much less than when using pitch attitude. This indicates that the flying qualities are less sensitive to increasing demands of the maneuver when using vertical speed instead of pitch attitude. Therefore, the Neal/Smith analysis supports using direct pilot control of flightpath as opposed to direct control of pitch attitude.

Pilot evaluations of the SR-71 aircraft compare favorably with the Neal/Smith analysis using vertical speed in figure 10. The pilot ratings and comments of the SR-71 aircraft noted that leading the aircraft was required to acquire the target altitude during the vertical plane altitude change. One pilot commented that "a great deal of lead is required [to acquire the target altitude] in terms of time." However, the lead is not significant enough to reduce the ratings from level 1 to level 2 for the inertially derived vertical speed data (fig. 2). The Neal/Smith analysis using the vertical speed at the pilot station predicts level 1 flying qualities up to $1.5 \mathrm{rad} / \mathrm{sec}$ (category $\mathrm{C}$ bandwidth requirement) while requiring pilot lead. Direct pilot control of vertical speed could result in large, objectionable pitch rate overshoots.

Figure 11 presents a step input into a validated batch simulation at Mach 3 to illustrate the pitch rate overshoot that occurs when a small vertical speed increment is made. No pilot comments indicating an abrupt initial response were noted. Thus, pilot ratings and comments appear to be based on the vertical speed response, while the pitch attitude response goes unnoticed. Although the 


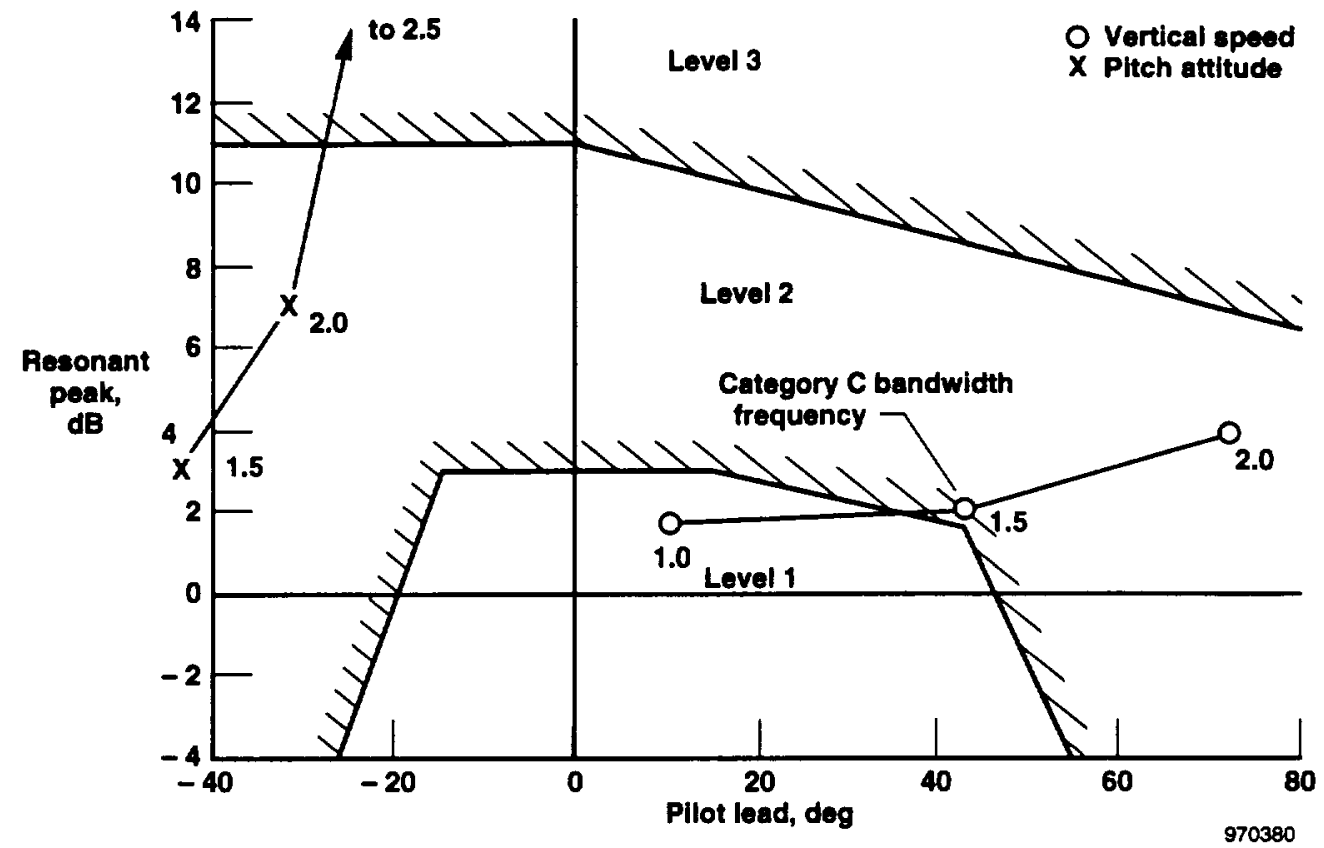

Figure 10. Neal/Smith results using pitch attitude and vertical speed from stick position frequency responses as a function of bandwidth frequency.
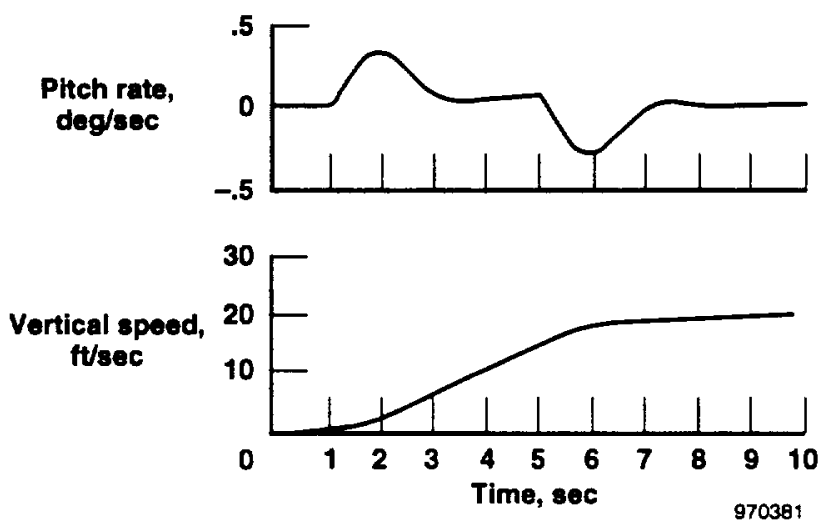

Figure 11. Comparison of pitch rate and vertical speed responses at Mach 3. 


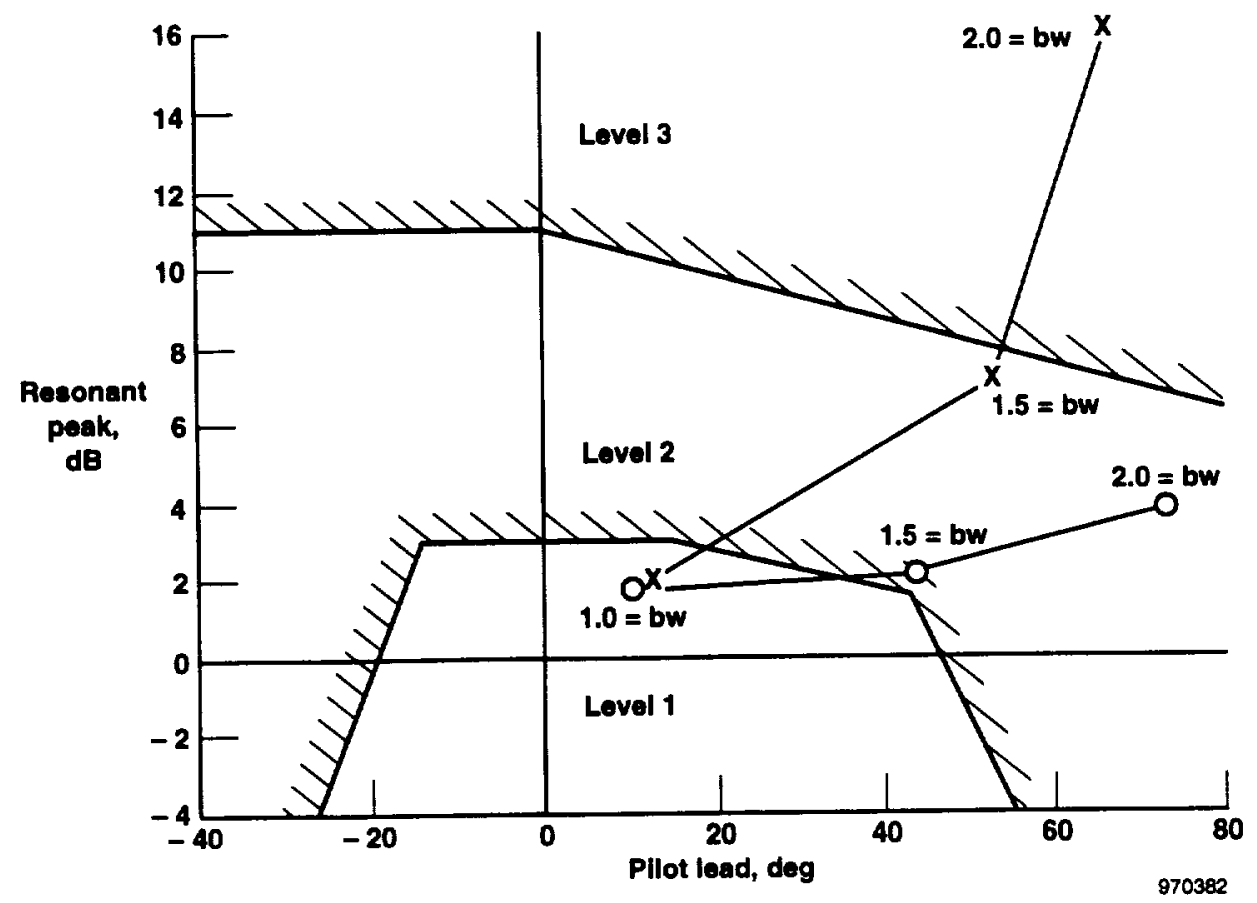

Vertical speed at pilot station

$X$ Vertical speed at c.g.

Figure 12. Neal/Smith analysis of the vertical speed at the center of gravity and the vertical speed at the pilot station to stick deflection frequency response.

pitch rate overshoots are relatively large, the absolute magnitude of the pitch attitude changes are small at high speeds, so the overshoot characteristics are not a factor in pilot opinion.

The Neal/Smith analysis can also be used to illustrate the affect of the location of the inertial vertical speed measurement. Figure 12 shows the results for the inertial system in its present location near the cockpit and at the center of gravity. The cockpit location data provide lead due to the pitch acceleration, thereby reducing the amount of lead required by the pilot. The cockpit location data also reduce the sensitivity of the response for increased demands of the task.

\section{Conclusions}

Pilot comments and ratings of the SR-71 aircraft flown at Mach 3 were collected using a vertical plane altitude change and compared to established handling qualities criteria. The objective of this study was to extend some of the supersonic flying qualities research conducted 25 years ago with the XB-70 and YF-12 programs using these new data. Analysis of pilot displays of vertical speed critical to performing the maneuvers and comparisons of the pilots' ability to directly control pitch attitude and flightpath were among the issues specifically addressed in this study. The following results are reported:

1. The pilots' ability to perform the maneuvers was strongly influenced by the information displayed to the pilot. Feedback of vertical speed based on an inertial reference frame was critical to the pilots' ability to perform accurate flightpath control. Pilot ratings and comments of maneuvers flown with a pressure-driven vertical speed indicator showed that performance was significantly degraded.

2. Analysis indicates that direct pilot control of flightpath for a conventional airplane in supersonic flight has significant advantages over pilot control of pitch attitude. A modification of the Neal/Smith analysis using the vertical speed at the pilot station as feedback for pilot control produced level 1 results for a bandwidth up to $1.5 \mathrm{rad} / \mathrm{sec}$. Pilot ratings and comments are consistent with the level 1 Neal/Smith analysis using vertical speed at the pilot station. In comparison, the analysis using pitch attitude feedback to the pilot produced level 2 results for the same bandwidths. In addition, the large shelf in the pitch attitude from stick deflection frequency response, typically associated with poor flying qualities, supported the Neal/Smith analysis using pitch attitude frequency response. 
3. Application of criteria on pitch attitude and flightpath bandwidth was inconclusive in the evaluation of pitch attitude and flightpath control. Although the pitch bandwidth criterion showed good pitch attitude control was possible and correlated with pilot ratings, this criterion may not be sufficient to predict good supersonic flying qualities. Ratings were based on flightpath control using vertical speed indications to the pitot.

4. Application of the flightpath bandwidth criterion showed that good flightpath control using pitch attitude was possible. However, the flightpath bandwidth analysis was inconsistent with degraded high-speed SAS turned off ratings and comments. The SAS turned off flightpath bandwidth data fall above the minimum level 1 value in a region where flying qualities limits are defined by poor consonance between pitch attitude and flightpath in the approach and landing phase. This factor may not be as influential for the high-speed evaluations because the pilots used direct feedback of vertical speed in cruise.

\section{References}

1 "Flying Qualities of Piloted Airplanes," Military Specifications MIL-STD-8785B, Aug. 1969.

2 Berry, Donald T., "Some Handling Qualities Problems of Supersonic Cruise Aircraft," Proceedings from NASA
Aircraft Safety and Operating Problems Conference, vol. 2, NASA SP-271, May 1971, pp. 25-38.

${ }^{3}$ Berry, Donald T., "A Summary of YF-12 Handling Qualities," YF-12 Experiments Symposium, NASA CP-2054, Sept. 1978, pp. 31-57.

${ }^{4}$ Berry, Donald T., Donald L. Mallick, and Glenn B. Gilyard, "Handling Qualities Aspects of the NASA YF-12 Experience," Proceedings of SCAR Conference, NASA CP-001, Nov. 1976, pp. 193-213.

${ }^{5}$ Berry, Donald T. and B. G. Powers, "Flying Qualities of a Large, Supersonic Aircraft in Cruise and Landing Approach," AIAA 70-566, May 1970.

${ }^{6}$ Berry, Donald T. and G. Gilyard, "Airframe/Propulsion System Interactions-An Important Factor in Supersonic Aircraft Flight Control," AIAA 73-831, Aug. 1973.

${ }^{7}$ Cox, Timothy H. and D. Jackson, Evaluation of High Speed Civil Transport Handling Qualities Criteria with Supersonic Flight Data, NASA TM-4791, Apr. 1997.

8 "Flying Qualities of Piloted Vehicles," Military Specifications MIL-STD-1797, Mar. 1987.

9 Hoh, Roger H., "Recommendations for Approach and Landing Flying Qualities," Systems Technology, Inc., Hawthorne, California, Working Paper 2631-1, Dec. 1988. 
Public reporting burden for this collection of information is estimated to average 1 hour per response, including the time tor reviewing instructions, searching existing data sources, gathering and maintaining the dats nored, and completing and reviewing the coltection of intormation. Send comments regarding this burden estimate or any other aspect of this collection of intormation. including sugoestions for reducing this burden, to Washington Headquarters Services. Directorate for Intormation Operations and Peports, 1215 Jetterson Devis Highway, Suite 1204 , Arlington, VA 22202-4302, and to the Otfice of Management and Budgat. Papenwork Reduction Project (0704-0188), Washington, DC 20503.

\begin{tabular}{|l|l|c|}
\hline 1. AGENCY USE ONLY (Leave blank) & 2. REPORT DATE \\
August 1997 & $\begin{array}{c}\text { 3. REPORT TYPE AND DATES COVERED } \\
\text { Technical Memorandum }\end{array}$
\end{tabular}

\section{TITLE AND SUBTITLE}

August 1997

Technical Memorandum

Supersonic Flying Qualities Experience Using the SR-71

6. AUTHOA(S)

WU 5295024

Timothy H. Cox and Dante Jackson

7. PERFORMING ORGANIZATION NAME(S) AND ADDRESS(ES)

6. PERFORMING ORGANIZATION

REPORT NUMBER

NASA Dryden Flight Research Center

P.O. Box 273

Edwards, California 93523-0273

$\mathrm{H}-2178$

9. SPONSORINGMONITORING AGENCY NAME(S) AND ADDRESS(ES)

10. SPONSORINGMONITOAING

AGENCY REPOAT NUMBER

National Aeronautics and Space Administration

Washington, DC 20546-0001

NASA TM-4800

\section{SUPPLEMENTAFY NOTES}

Presented as AIAA 97-3654 at the AIAA Atmospheric Flight Mechanics Conference, New Orleans, Louisiana, August 11-13, 1997.

Timothy H. Cox, Dryden Flight Research Center, Edwards, California: Dante Jackson, Analytical Services and Material, Inc., Edwards, California.

12. DISTRIBUTIONAVAILABILTYY STATEMENT

12b. DISTRIBUTION CODE

Unclassified-Unlimited

Subject Category 08

13. ABSTRACT (Maximum 200 words)

Approximately 25 years ago NASA Dryden Flight Research Center, Edwards, California, initiated the evaluation of supersonic handling qualities issues using the XB-70 and the YF-12. Comparison of pilot comments and ratings with some of the classical handling qualities criteria for transport aircraft provided information on the usefulness of these criteria and insight into supersonic flying qualities issues. A second research study has recently been completed which again addressed supersonic flying qualities issues through evaluations of the SR-71 in flight at Mach 3. Additional insight into supersonic flying qualities issues was obtained through pilot ratings and comments. These ratings were compared with existing military specifications and proposed criteria for the High Speed Civil Transport. This paper investigates the disparity between pilot comments and the Neal/Smith criteria through a modification of the technique using vertical speed at the pilot station. The paper specifically addresses the pilot ability to control flightpath and pitch attitude in supersonic flight and pilot displays typical of supersonic maneuvering.

\begin{tabular}{|c|c|c|c|}
\hline \multirow{2}{*}{\multicolumn{3}{|c|}{$\begin{array}{l}\text { 14. SUBJECT TERMS } \\
\text { Bandwidth criteria, Flightpath bandwidth, Flying qualities, High Speed Civil } \\
\text { Transport, Neal/Smith criteria, SR-71 aircraft, Supersonic flying qualities. }\end{array}$}} & \multirow{2}{*}{\begin{tabular}{|c|}
$\begin{array}{l}\text { 15. NUMBER OF PAGES } \\
15\end{array}$ \\
$\begin{array}{c}\text { 16. PRICE CODE } \\
\text { A03 }\end{array}$ \\
\end{tabular}} \\
\hline & & & \\
\hline $\begin{array}{l}\text { 17. SECURITY CLASSIFICATION } \\
\text { OF REPORT }\end{array}$ & $\begin{array}{l}\text { 18. SECURITY CLASSIFICATION } \\
\text { OF THIS PAGE }\end{array}$ & $\begin{array}{l}\text { 19. SECUAITY CLASSIFICATION } \\
\text { OF ABSTRACT }\end{array}$ & 20. LIMTTATION OF ABSTRACT \\
\hline Unclassified & Unclassified & Unclassified & Unlimited \\
\hline
\end{tabular}

